\title{
2013 Award for an Exemplary Program or Achievement in a Mathematics Department
}

The recipient of the 2013 Award for an Exemplary Program or Achievement in a Mathematics Department is the DEPARTMENT OF MATHEMATICS AT THE UNIVERSITY OF TEXAS AT ARLINGTON. What follows is the selection committee's citation.

\section{Citation}

The American Mathematical Society is pleased to recognize the Department of Mathematics at the University of Texas at Arlington with the 2013 Award for an Exemplary Program or Achievement by a Mathematics Department. The mathematics department at UT-A has made a concerted and highly successful effort over the last decade to build a doctoral program whose composition reflects the demographics of our increasingly diverse nation. During the period 2005-2010 the department more than doubled its number of full-time, funded doctoral students and substantially increased its percentage of U.S. citizens and permanent residents, women and minorities (see table below).

During this period, the department granted the doctoral degree to twenty-six students of whom fifteen were U.S. citizens, seven were underrepresented minorities and eight were women. By making this transformation, the mathematics department at UT-A joined a handful of mathematics departments, all of them in regions quite remote from Texas, who have had similar success in building diverse doctoral programs. Thus, in addition to contributing significantly to the national effort to increase the number of doctoral degrees in mathematics awarded to U.S. citizens and, especially to U.S. women and students from backgrounds traditionally underrepresented in mathematics, the department at UT-A has also played an increasingly important role in carrying out this effort in its region. Indeed, departmental faculty are helping to organize a regional Gulf States Alliance that will work with the National Alliance for Doctoral Studies in the Mathematical Sciences to ensure that every student in the Gulf States region who has the desire and the talent to earn a doctoral degree in mathematics will have the opportunity to do so.

The success of the mathematics department at UT-A in transforming its doctoral program may be attributed to several factors, all of which should be replicable at departments with similar missions and demographics. Perhaps the most important of these factors is broad support and participation by faculty. For example, during the last three years, ninety-seven percent of departmental faculty either supervised a graduate student or served as a PI or co-PI on a doctoral student training grant. This broad faculty support has enabled the department to put in place a highly successful mentoring program as well as a strong professional development program. A second factor is the department's success in locating funding for its efforts. It has worked closely with UT-A administrators who have supported the department's efforts and it has also received more than four million dollars from competitive external doctoral fellowship grants.

The purpose of the Award for an Exemplary Program or Achievement by a Mathematics Department is to recognize a department that has distinguished itself by undertaking an unusual

\begin{tabular}{|c|l|l|l|l|}
\hline Year & $\begin{array}{l}\text { Doctoral Students } \\
\text { (total) }\end{array}$ & $\begin{array}{l}\text { U.S. Citizens or } \\
\text { Permanent Residents }\end{array}$ & Women & $\begin{array}{l}\text { Underrepresented } \\
\text { Minority Students }\end{array}$ \\
\hline 2005 & 23 & 9 & 5 & 1 \\
\hline 2010 & 52 & 29 & 20 & 8 \\
\hline
\end{tabular}

DOI: http://dx.doi.org/10.1090/noti1004 
or particularly effective program of value to the mathematics community, internally or in relation to the rest of society.

In building and sustaining a first-rate, diverse doctoral program, the mathematics department at the University of Texas at Arlington certainly meets this criterion. In addition, the department has become a national and a regional leader in the effort to increase the number of American students of all backgrounds who earn a doctoral degree in mathematics. It is for these reasons that this department is so deserving of this award.

\section{About the Award}

The Award for an Exemplary Program or Achievement in a Mathematics Department was established by the AMS Council in 2004 and was given for the first time in 2006. The purpose is to recognize a department that has distinguished itself by undertaking an unusual or particularly effective program of value to the mathematics community, internally or in relation to the rest of society. Departments of mathematical sciences in North America that offer at least a bachelor's degree in mathematical sciences are eligible. Through the generous support of an anonymous donor, the award carries a cash prize of US\$5,000.

The award is presented by the AMS Council acting on the recommendation of a selection committee. For the 2013 award, the members of the selection committee were: Carlos Castillo-Chavez, Annalisa Crannell, Phil Kutzko (chair), Suzanne Marie Lenhart, and Francis Edward Su.

The previous recipients of the award are Harvey Mudd College (2006), the University of California, Los Angeles (2007), the University of Iowa (2008), the University of Nebraska, Lincoln (2009), North Carolina State University (2010), the Math Center at the University of Arizona (2011), and Bryn Mawr College (2012).

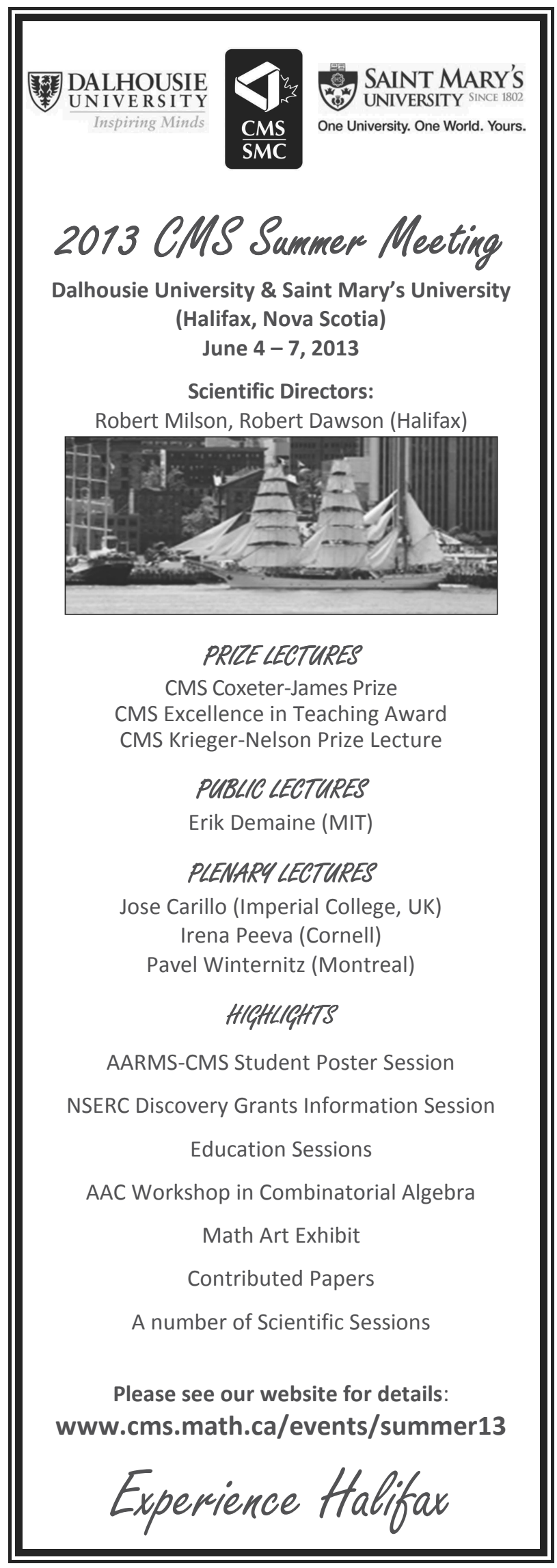

